Instructions for authors, subscriptions and further details:

http://brac.hipatiapress.com

\title{
Heroínas de una Sociedad Misógina. Teresa de Jesús Atrincherada en la Morada. Mística en el Arte Contemporáneo
}

Natividad Navalón, Alejandro Mañas, Teresa Cháfer ${ }^{1}$

1) Facultad de Bellas Artes, Universidad Politécnica de Valencia. España

Date of publication: February $3^{\text {rd }}, 2017$

Edition period: February 2017-June 2017

To cite this article: Navalón, N., Mañas, A., \& Cháfer, T. (2017). Heroínas de una sociedad misógina. Teresa de Jesús atrincherada en la morada.

Mística en el arte contemporáneo. Barcelona, Research, Art, Creation, 5(1), 17-44. doi: 10.17583/brac.2017.2365

To link this article: http://dx.doi.org/10.17583/brac.2017.2365

PLEASE SCROLL DOWN FOR ARTICLE

The terms and conditions of use are related to the Open Journal System and to Creative Commons Attribution License (CC-BY). 
pp. 17-44

\section{Heroines in a Misogynistic Society. Teresa of Jesus Barricaded in the Mansion. Mysticism in Contemporary Art}

Natividad Navalón, Alejandro Mañas, Teresa Cháfer. Faculty of Fine Arts, Polytechnic University of Valencia. Spain

(Received: 24 October 2016; Accepted: 18 December 2016; Published: 3 February 2017)

\section{Abstract}

This article is the first in a series of reflections in which our main objective is the recovery of space that should never lose women. We review those heroines women in a misogynist society, who have been influential thinkers in the creative work of contemporary art. This text is dedicated to Saint Teresa of Jesus, a heroine, in whom many artists have set their sights as a benchmark for empowerment and they have directed their work toward mysticism, creating a connection between art and spirituality. We collect a selection of artists who have used the mystical, pain, purple, silence, visions, and finally, ecstasy, in their creative process, to give voice to a gender problem in this society and to work in the struggle for the recovery of a space that had always belonged to women. Artists who, through their work, claim a place in a society culturally articulated by man. They are a clear example of what we have called heroines women in a misogynist society.

Keywords: art, mysticism, spirituality, feminism

2017 Hipatia Press

ISSN: 2015-8992

DOI: $10.17583 /$ brac. 2017.2365

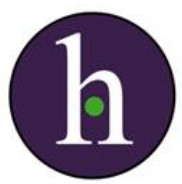


pp. 17-44

\section{Heroínas en una Sociedad Misógina. Teresa de Jesús Atrincherada en la Morada. Mística en el Arte Contemporáneo}

Natividad Navalón, Alejandro Mañas, Teresa Cháfer Facultad de Bellas Artes, Universidad Politécnica de Valencia. España

(Recibido: 24 octubre 2016; Aceptado: 18 diciembre 2016; Publicado: 3 febrero 2017)

\section{Resumen}

Este artículo es el primero de una serie de reflexiones en las que nuestro objetivo principal es la recuperación del espacio que no debió perder nunca la mujer. En él hacemos una revisión de aquellas mujeres heroínas, combatientes en una sociedad misógina, que han sido pensadoras influyentes en la labor creadora desarrollada por mujeres artistas contemporáneas. Este texto está dedicado a santa Teresa de Jesús, una heroína, en la que numerosas artistas han puesto su mirada como referente de empoderamiento y han dirigido su trabajo plástico hacia el misticismo, generando una conexión entre arte y espiritualidad. Recogemos una selección de artistas que se han servido de la mística, el dolor, la morada, el silencio, las visiones y, por último, el éxtasis en su proceso creativo, para dar voz a un problema de género en esta sociedad y para trabajar en la lucha por la recuperación de un espacio que siempre debió pertenecer a la mujer. Artistas que, a través de su trabajo, reivindican un hueco en una sociedad falocentrista. Ellas son un claro ejemplo de lo que hemos denominado mujeres heroínas en una sociedad misógina.

Palabras clave: arte, misticismo, espiritualidad, feminismo 


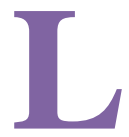

a historia del hombre ha sido siempre la historia de "el hombre" como género masculino (Navalón \& Mañas, 2016, p. 211). En el ámbito en el que desarrollamos nuestra investigación también ha transcurrido así, la historia del arte no ha dejado hueco a la acción realizada por la mujer hasta bien entrado el siglo XX, porque la propia sociedad no le ha permitido expresarse, ni tan siquiera ha reconocido la labor de aquellas que batallaron por ello. "La historia de la reivindicación de heroínas y figuras célebres tiene su origen en los inicios de la modernidad, que en su transcurso queda pespunteada por escritos e imágenes de mujeres, conscientes de la necesidad de mantener un legado y continuar apuntalando una tradición propia.” (Solana, Villa, Gallardo \& Valcárcel, 2011, p. 59).

Han sido numerosas las mujeres que se han dejado la piel en su lucha por la igualdad, la libertad y la justicia. Mujeres que han resuelto empresas hasta entonces reservadas al hombre. Mujeres que han reivindicado su lugar en la sociedad. Ésta ha sido siempre una labor en soledad, tarea donde interviene la dedicación, el sacrificio, el dolor, pero sobre todo la generosidad de quienes cedieron su empeño y su vida para que otras pudieran recuperar parte de ese espacio que siempre debió pertenecer a la mujer. Mujeres que, como Teresa de Jesús, Christine de Pizan, Juana de Arco o Hildegarda de Bingen, “(...) fueron ninguneadas o, en el mejor de los casos, utilizadas por la política, la iglesia y la sociedad en beneficio de sus propios intereses que nada tenían que ver con las aspiraciones y objetivos de sus protagonistas" (Luceño \& Dorfstecher, 2015, p. 3). Mujeres que han ejercido una gran influencia en esta lucha contra la discriminación, que han servido de guía o de motivación a otras muchas que, en la actualidad batallan por la identidad y por la igualdad o la diferencia a través de su labor en el campo del arte, una herramienta que se convierte en arma para dar voz a aquellas que no tienen la posibilidad de hacerlo. Ellas son mujeres combativas, es por ello el título de este artículo, heroínas. Heroínas en una sociedad misógina.

Este artículo está dedicado a la influencia de Teresa de Cepeda y Ahumada en el ámbito de la creación artística contemporánea. Tanto filósofas, historiadoras, como comisarias o artistas reivindican la vigencia de una figura, la mayoría de las veces relegada al santoral, que desafió las imposiciones que su época le exigía y se adelantó a su tiempo. Por ello, en 
este artículo queremos evidenciar la labor de una mujer transgresora, el pensamiento de una mujer intelectual y la influencia que ha ejercido y ejerce en el arte contemporáneo y, en especial, en las mujeres artistas.

Esta mujer tenaz y perseverante se ha convertido en un símbolo universal, es la primera mujer Doctora de la Iglesia. "En un mundo misógino como aquel del siglo XVI, Teresa de Jesús supo marcar sus fronteras y hacer valer su condición de mujer donde quiera que estuviese.” (Ros, 2011, p. 10). Desde muy joven, su espíritu rebelde la llevó a saltarse todas las normas y prohibiciones que fuera menester para lograr sus fines, fue un ejemplo para las finanzas, fundó 17 conventos, luchó por la inserción social buscando siempre la igualdad. Teresa de Jesús fundó también conventos de frailes. Era ella quien elegía a los hombres y, entre ellos, a san Juan de la Cruz para llevar a cabo sus proyectos. Este testimonio es relatado en su libro Fundaciones, en el que podemos comprobar cómo su afán de implantar nuevas casas la llevó a enfrentarse a dirigentes y nobleza; incluso en la organización de las construcciones de conventos supervisaba cada una de las obras. Emprendió un camino decisivo de constante lucha en una sociedad que estaba regida por hombres, donde ella, con sus armas y tesón, defendió con valentía sus valores e iniciativas.

Mujer emprendedora, pero también intelectual, una pensadora en su tiempo. Sus escritos son el testimonio de sus hazañas y meditaciones que tienen un eje común, la espiritualidad, un camino de búsqueda. Esta búsqueda, esta experiencia mística, la ostentación de lo inefable, la llevó a estar frente a la Inquisición. Queremos evidenciar que Teresa de Jesús no dejó de escribir sus textos a pesar de la recomendación negativa de algunos de sus confidentes. La misoginia del siglo XVI se movía especialmente en torno a la incapacidad intelectual femenina y su inferioridad para la enseñanza de las cosas espirituales. Teresa transgrede sin temor las leyes que su tiempo le impone por su condición de mujer. Quebranta la prohibición, impuesta a las mujeres, de leer textos sagrados. Desoye la obligación, impuesta a las mujeres, de rezar únicamente en voz alta (repetir) y defiende la oración interior (pensar).

¿No basta, Señor, que nos tiene el mundo acorraladas, que no hagamos cosa que valga nada por vos en público ni osemos hablar algunas verdades que lloramos en secreto, sino que no 
nos habíais de oír petición tan justa? No lo creo yo, Señor, de vuestra bondad y justicia, que sois justo juez y no como los jueces del mundo, que como son hijos de Adán y, en fin, todos varones, no hay virtud de mujer que no tengan por sospechosa. Sí, que algún día ha de haber, Rey mío, que se conozcan todos. No hablo por mí, que ya tiene conocido el mundo mi ruindad, y yo holgado que sea pública; sino porque veo los tiempos de manera que no es razón desechar ánimos virtuosos y fuertes, aunque sean de mujeres". (Teresa de Jesús. Camino de Perfección [ms. de El Escorial] 4,1)

En las últimas décadas, Teresa de Jesús se ha convertido en un icono feminista para el mundo occidental, no sólo porque ha llegado a representar el eslabón perdido entre la espiritualidad y la sexualidad femenina, sino también por su capacidad para resolver sus empresas y desenvolverse, aunque sea sesgadamente, dentro de una sociedad con una jerarquía dominada por los varones. Fue una mujer capaz de llegar a la autodegradación para lograr sus objetivos sin hacer peligrar su condición y posición en cada momento, construyendo una versión de sí misma aceptable para la Inquisición. Simone de Beauvoir manifiesta en El segundo sexo:

\begin{abstract}
(...) Santa Teresa trata de unirse con Dios y vive esa unión en su cuerpo; no es esclava de sus nervios y sus hormonas; más bien hay que admirar en ella la intensidad de una fe que penetra hasta lo más íntimo de su carne. En verdad, como había comprendido la propia Santa Teresa, el valor de una experiencia mística se mide, no según la manera en que ha sido subjetivamente vivida, sino según su alcance objetivo. (Beauvoir, 2003, p. 843)
\end{abstract}

Teresa de Jesús, como todos sabemos, es un claro exponente universal de la mística. A través de este tipo de experiencia alcanza el grado máximo de unión del alma humana a lo sagrado durante la existencia terrenal. Una experiencia a la que la santa llega a través de su constancia, entrega, meditación, contemplación y sacrificio. Y con ello, un camino de 
comprensión, de renuncia, de ensimismamiento, del cual se desprende un amor absoluto hacia sus ideales y hacia lo sagrado. Es un camino progresivo que culmina con el éxtasis.

La mística, en su forma pura, es la ciencia de las cosas últimas, la ciencia de la unión con lo absoluto y nada más. Hablar de mística es hablar de espiritualidad, pero también aludir a lo secreto, arcano, oculto, impenetrable, donde se sitúa la unión con lo absoluto, es hablar de una búsqueda interior a través del misterio, a través de las profundidades del ser, es hablar de aislamiento, de silencio, es hablar de exilio. Este encuentro y práctica de la mística se sirve de herramientas como la meditación y la disciplina ascética, un hecho que se produce en la mayoría de las religiones del mundo y no religiones, un hecho que también se da en la vida cotidiana y laicista.

Las artes plásticas mantienen una doble relación con la mística: por una parte, aquellas extraídas a partir del proceso de creación y, por otra, la plasmación o traducción en imágenes visuales. Glòria Picazo nos señala, "Y puede que sea en este punto donde la identificación entre misticismo y creación artística haya encontrado su punto de convivencia: el hecho de poder trabajar en la búsqueda de lo transcendente de los límites." (Picazo, 2001, p. 69). El proceso místico lo podemos encontrar en periodos de actividad artística e intelectual; esa labor creadora, supone al artista, tal y como nos describe Evelyn Underhill, un retrato de la personalidad mística: “(...) el místico típico parece ir hacia su meta a través de una serie de oscilaciones fuertemente marcadas entre «estados de placer»y «estados de dolor»." (Underhill, 2006, p. 194). Estos momentos son clave e importantes para la actividad de la mística, pero sobre todo en el proceso de creación.

La espiritualidad, lo inmaterial, lo inefable son propuestas que han estado presentes a lo largo de la historia del arte, pero han sido en los siglos XX y XXI cuando conceptos como sacralidad, espíritu, contemplación, meditación y misticismo han renacido como propuestas artísticas fuertes. Angela Vettesse, nos apunta cómo el arte conceptual retoma el misticismo al adentrarse en un camino que va más allá de la razón:

No es casual que el misticismo, como toma de conciencia de la incapacidad de conocer todo a través de la razón, emerja de nuevo en el arte conceptual. En 1967, Bruce Nauman escribió en una famosa espiral de tubos de neón: «El verdadero artista 
ayuda al mundo revelando verdades místicas». Sol Lewitt abre sus Sentencias on Conceptual Art, de 1969, diciendo: «1. Los artistas conceptuales son místicos, más que racionalistas. 2. Llegan a conclusiones a las que la lógica no puede llegar. 3. Los juicios irracionales llevan a una nueva experiencia». En la intervención titulada Qué me piensa ahora (What Thinks Me Now), en 1982, de John Baldessari para la Documenta 7, se citan frases como: «Quiero re-encantar y re-mitologizar. Estoy interesado en un arte como camino de conocimiento. Quiero conocer la matriz de los eventos de la historia. Quiero trabajar en la espiritualización de la materia y en la materialización del espíritu. Quiero considerar el lenguaje como una articulación de lo limitado para expresar lo ilimitado». (Vettesse, 2013, p. 196)

Innumerables son las exposiciones que han tenido como tema central el misticismo o lo espiritual en el arte, entre ellas podemos señalar The Spiritual in Art: Abstract Painting 1809-1985, celebrada en el Country Museum of Art de los Ángeles en 1986 y comisariada por Maurice Tuchman. Exposición que mostró la asociación entre abstracción y espiritualidad y sirvió para valorar la significación del propio arte abstracto.

En los últimos años, en nuestro país se han llevado a cabo numerosas exposiciones centradas en esta temática, El gran silencio, 2015, en el Centro Andaluz de Arte Contemporáneo (CAAC); Arte y espiritualidad, 2013, en el Instituto Valenciano de Arte Moderno (IVAM); Silencis silos, 2008, organizada por el Museo Nacional Centro de Arte Reina Sofía (MNCARS) o El instante eterno. Arte y espiritualidad en el cambio del milenio, realizada en el Espai d’Art Contemporani de Castelló (EACC), en 2001. José Miguel G. Cortés, director del EACC en aquellos momentos, afirmó que:

Son muchos los creadores, en muy diferentes disciplinas, los que en los últimos cien años han estado involucrados en el deseo de plasmar o reflejar en sus obras las ideas y los misterios ofrecidos por los escritores espirituales, las ideas metafísicas o los diferentes sistemas de creencias religiosas. (Picazo, Cortés \& Mascaró, 2001, p. 13) 
Exposiciones, todas ellas, que nos hablan de lo transcendente y espiritual en el arte, del misterio del ser humano. Los artistas comparten la inquietud por lo inefable, nos hablan del silencio, el vacío, la muerte, el tiempo, lo sagrado y de lo transcendente, de un camino íntimo de introspección en soledad, conceptos todos ellos presentes en los textos de Teresa de Jesús.

Numerosas disciplinas han fijado su mirada concretamente en la figura de Teresa de Jesús, sus manuscritos como las Moradas, Fundaciones o Libro de la vida han sido los referentes para muchas creaciones. Desde el cine mudo Escenas de la vida de Santa Teresa, 1926, de Francisco Beringola (sólo se conservan 13 minutos); Teresa de Jesús, 1962, dirigida por Juan de Orduña durante el régimen franquista; la serie para RTVE Teresa de Jesús, 1984, de Josefina Molina; hasta películas más recientes como Teresa, Teresa, 2003, cuyo director y guionista fue Rafael Gordon o la película La mística hecha palabra. Santa Teresa de Jesús, escritora, 2011, producida por Vicis SRL y dirigida por Graziano dal Maso. También Dalí puso los ojos en Santa Teresa, con el afán de dirigir a Greta Garbo en una película sobre Teresa de Ávila que nunca llegaría a producirse. Fuera de nuestro país nos encontramos Visions of Ecstasy, 1989, del británico Nigel Wingrove, desde una perspectiva mucho más erótica basada en la escultura de Bernini, donde los éxtasis rozan el erotismo (en España: Teresa: el cuerpo de Cristo, de Ray Loriga, 2007). En los últimos años han dirigido su mirada hacia Teresa de Jesús otros cineastas como Pablo Frasconi, Eduardo DeFilippis o Lorenzo Leín Díez. "Incluso sería posible destacar la aparición del personaje en uno de los episodios de la conocida serie estadounidense The Simpson, parodia de las conspiraciones histórico-religiosas tan habituales en bestsellers como El código da Vinci." (Mingo \& Hernández, 2015, p. 14). También el teatro, la danza o la música han trabajado sobre la figura de la santa. Durante el V centenario de Santa Teresa de Jesús, un sinfín de disciplinas se han hecho eco de ella.

Dentro de las artes plásticas nos gustaría destacar tres de las últimas exposiciones que se han realizado en nuestro país, donde encontramos a Teresa de Jesús como objeto de estudio, en ellas se ha revisado la figura de la mística y se han aportado nuevos enfoques a esta Doctora de la Iglesia a partir de su literatura, de su proceso místico y de su posicionamiento ante la vida. La primera de ellas es la exposición Teresa de Ávila. Mística y 
transgresora, 2015, celebrada en Palacio de Pimentel y comisariada por Guadalupe Luceño e Ilse-María Dorfstecher. En esta muestra que participan 20 mujeres de diez países diferentes, Teresa sale triunfadora como ejemplo de mujer feminista y luchadora. En ella se reivindica un "feminismo teresiano" (Luceño \& Dorfstecher, 2015, p. 4). También queremos señalar la exposición concebida para clausurar los actos con motivo del V Centenario del nacimiento de Santa Teresa de Jesús, Nada temas, dice ella. Cuando el arte revela verdades místicas, 2015, comisariada por Rosa Martínez. "Su verso «Nada te turbe, nada te espante», cargado de resonancias del siglo XVI, se convirtió en el más sencillo y contemporáneo «Nada temas», que estimula sutilmente la valentía necesaria para vivir, para destruir viejos esquemas y explorar caminos nuevos". (Martínez et al., 2015, p. 41). Obras que nos invitan a reflexionar sobre la inmanencia, la transcendencia, el dolor, el sufrimiento, que nos hablan de la conexión con aquello que está al otro lado. Por último, quisiéramos destacar la exposición Heroínas, 2011, comisariada por Guillermo Solana que aborda a la mujer como heroína desde varios aspectos: Solas, Cariátides, Ménades, Atletas, Acorazadas, Amazonas, Magas, Mártires, Lectoras, Pintoras y Místicas.

La historia del arte occidental abunda en imágenes de mujeres seductoras, complacientes, sumisas, vencidas, esclavizadas. Pero el objeto de nuestra exposición son las figuras de mujeres fuertes: activas, independientes, desafiantes, inspiradas, creadoras, dominadoras, triunfantes. O bien, para usar una palabra clave de la agenda feminista en las últimas décadas: esta exposición se interesa por aquellas imágenes que pueden ser fuentes de "empoderamiento" (empowerment) para las propias mujeres. (Solana, 2011, p. 18)

Muchas son y han sido las artistas que han tratado el tema de la espiritualidad en sus obras, pero nos vamos a centrar en aquellas que nos remiten a aspectos místicos, psíquicos, emocionales o físicos, atribuidos a la santa en su camino espiritual. Arrobamientos, levitaciones, éxtasis, y otros fenómenos son objeto de su representación y armas utilizadas en su lucha por dar visibilidad a la mujer. Artistas todas ellas capaces de emprender este 
viaje interior convertido, a veces en un encuentro con la identidad, otras en una cruzada por la igualdad o diferencia de la mujer. Para nosotros, mujeres heroínas cuya reivindicación y campo de batalla se muestra patente en su obra.

En este sentido, nos parece importante destacar la obra de la artista franco-italiana Gina Pane (Biarritz, Francia, 1939-1990) participante en la exposición El instante eterno. Arte y espiritualidad en el cambio del milenio o en El cuerpo abierto. Una mujer que utiliza como herramienta expresiva el cuerpo y el dolor, una artista que utiliza la lesión como lenguaje y efecto purificador, donde la herida condensa y define su trayectoria. Una postura de autoconocimiento, al igual que Santa Teresa, a través de la vía purgativa, donde su cuerpo se hará carne, y como tal, estará sujeto al placer y al dolor, tomará consciencia de las pulsaciones de la muerte y amorrará ante la infinitud, tratando mediante el sufrimiento (como los mártires y místicos cristianos) de fundirse con lo intemporal. A través del dolor se puede llegar al conocimiento, a una toma de conciencia del cuerpo que somos y de las limitaciones que la sociedad nos impone. (Aliaga, 2016)

La artista trabaja con una estética subversiva de la resistencia que le permite elaborar una mitología del sacrificio. Esta línea de trabajo fue extendida en los años sesenta y setenta por Europa y Norteamérica, denunciando el sufrimiento, la angustia y la consternación a la que viene abocada una sociedad. Gina, interesada por lo sagrado, convirtió este ámbito en una de las principales estructuras que sustentan su creación. En la obra Acción Psyché de 1974, realiza un trabajo dentro de Body-art, “(...) un campo de experimentación corporal que las acercó -señala Irene Ballesteros refiriéndose también a Marina Abramović- a experiencias místicas relacionadas con la práctica de una feminidad reprimida por patrones falocéntricos y les enlazó con las primeras santas místicas del cristianismo.” (Ballester, 2012, p. 27)

La obra de Gina titulada Azione Sentimentale, 1973, realizada en la galería Diagrama de Milán, explora la relación entre la marca del cuerpo y la cicatrización del paisaje, para demostrar la extrema fragilidad del ser y la realidad del sufrimiento. Los gestos simbólicos articulan su compromiso con el feminismo, políticas de identidad y el ecologismo. 


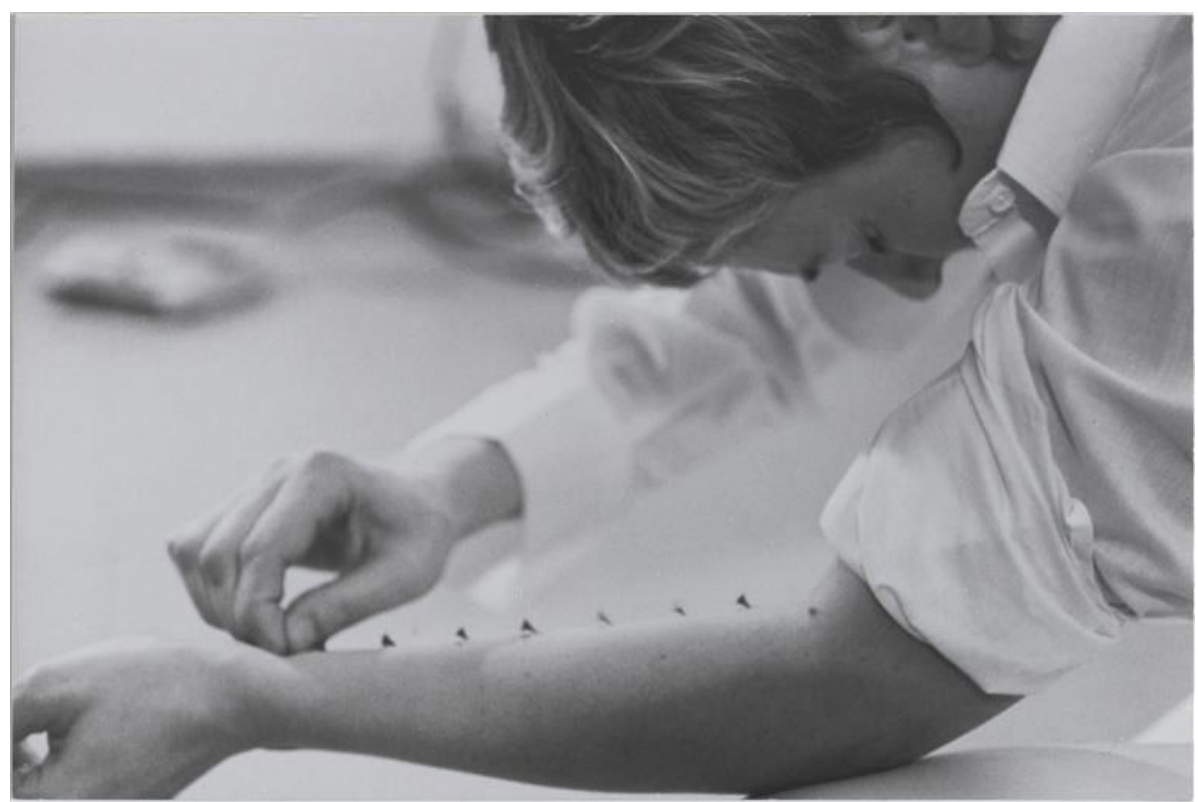

Figura 1. Gina Pane. Azione Sentimentale, (1973). (Detalle). Recuperada de http:// inasherahart.altervista.org/questione-corpo-body-art/

Su obra es toda una exploración en busca de un conocimiento propio, que pasará después a una reivindicación, donde el soporte es su propio cuerpo, cuerpo que mutila, araña, pincha y mortifica. Su cuerpo es la morada que permite renovar las fuerzas del inconsciente, la memoria de lo humano, de lo sagrado, del espíritu. Gina Pane se convierte en una mártir del dolor, que a través de sus performances da voz a la mujer.

La vida de los santos es importante para esta creadora, en quien encontró una analogía con el hombre contemporáneo. Los primeros, con sus vidas de pobreza, hambre o dolor y el hombre de hoy inserto en crueles realidades. La propia artista manifiesta su fascinación por los santos, porque entiende que estos hombres y mujeres han sobrepasado el límite del cuerpo carnal que sólo está arraigado en la tierra con los problemas de nuestro mundo. Su cuestionamiento de lo divino, de lo anímico, de lo vital, los aleja de lo banal y los sitúa en una esfera espiritual. Con esta temática, el Musée d'Art 
Moderne de Villeneuve-d'Asq de Francia en el año 1986, dedicó una exposición a su última obra, centrada en una mirada sobre santos y mártires.

En esta misma línea de trabajo donde aparece el dolor, la flagelación o la autolesión, encontramos la obra de Marina Abramović (Belgrado, República de Serbia, 1946). Sus propuestas podemos enmarcarlas, al igual que la artista anterior, en las quintas moradas. En ellas la santa nos narra sobre el dolor y la penitencia; moradas en las que emerge el dolor físico o psicológico, vía que los místicos utilizan para alcanzar un estado de éxtasis. La santa nos deja constancia de la dificultad del alcance de ese grado, donde es necesario desprenderse del ego, tarea difícil pero ineludible para continuar el viaje hacia el interior por un camino de hostilidad, en una constante lucha llena de tormento. En la obra de Abramović siempre ha habido reminiscencias de provocación, donde pone a prueba su resistencia ante una situación opresiva o peligrosa. La artista, a través de su propio cuerpo explora los límites, expresión que se encuentra vinculada a la resistencia física, psicológica, espiritual, para conseguir una "emoción con el universo, realmente místico". (Rico, 1998, p. 23)

La angustia, la tortura o el sacrificio son una constante en esta artista. En obras como Light / Dark, aparecen arrodillados Marina y Ulay bajo una iluminación tenue, dispuestos a abofetearse hasta que uno de los dos decida parar, como si de un martirio o tormento se tratase; en el vídeo titulado The Onion, observamos en un primer plano a la artista devorando una cebolla con enormes mordiscos, mientras su cara gestualiza el sufrimiento del ardor en la boca y el escozor en sus ojos; en la performance Ritmo 10, la artista con la mano abierta y apoyada en una mesa, va clavando rítmicamente un cuchillo entre sus dedos, cada vez que se cortaba cogía un cuchillo nuevo y empezaba la operación. En todas estas obras Marina Abramović explora los límites físicos del dolor, los límites entre la voluntad y la resistencia física.

Marina Abramović explora, además, esa consumación espiritual que llega en forma de éxtasis a la que hace alusión la santa. Desde esta perspectiva, la artista comparte el carácter teresiano en la disposición introspectiva que nos ofrece el libro titulado Moradas o Castillo interior, donde Teresa de Jesús arriesga, penetra y trata de comunicar la experiencia de ser y estar ante el mundo. 


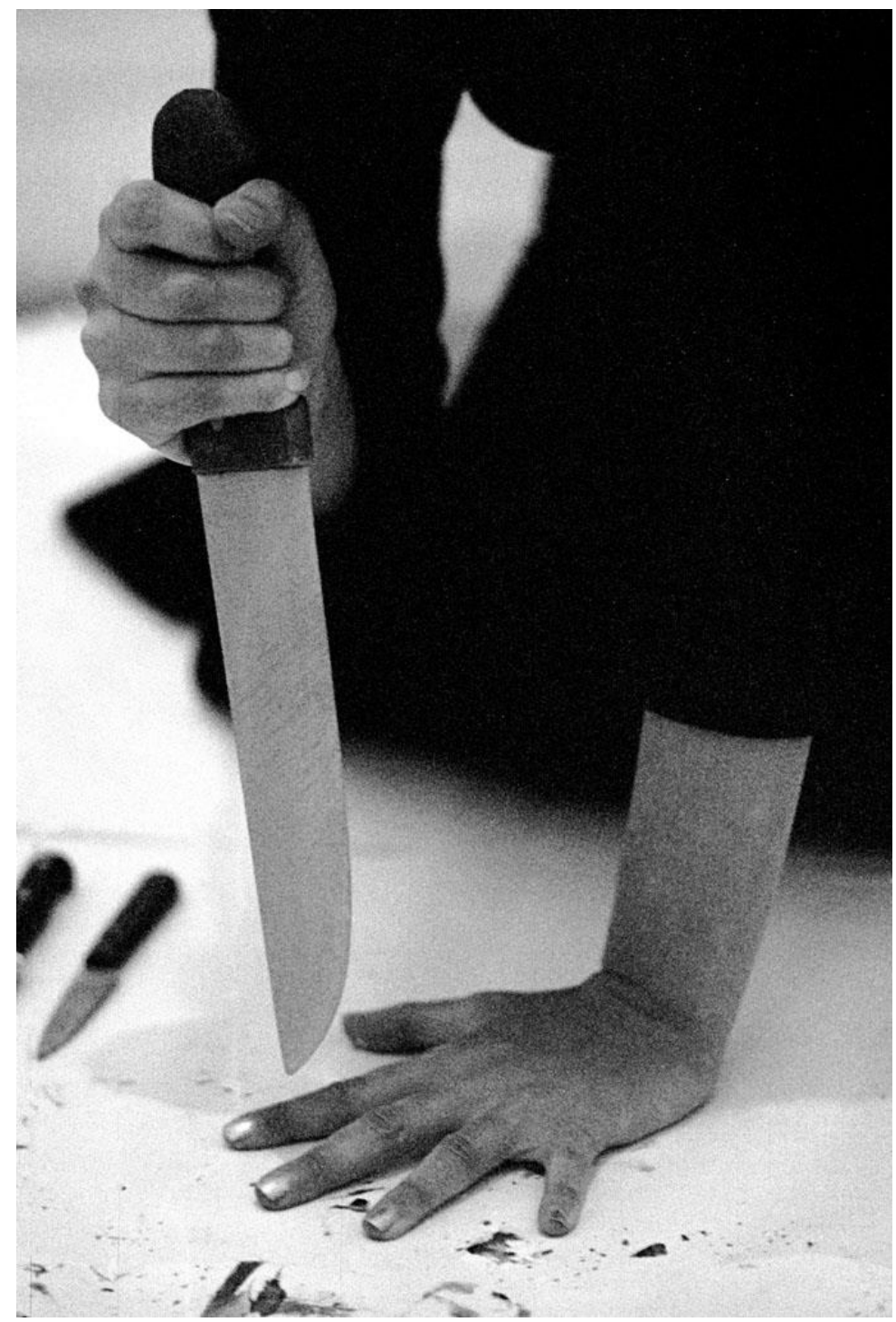

Figura 2. Marina Abramović. Ritmo 10, (1975). (Detalle). Recuperada de http://www.metalocus.es/es/noticias/marina-abramovic-en-la-fabricay-antony-and-johnsons-en-el-real 
Teresa de Jesús no es una mujer elegida por Marina Abramović al azar; la artista, con una infancia difícil, se crió con su abuela, una mujer muy religiosa, y se interesó por sus diarios. En su obra teatralizó lo que la santa narra en sus textos, la descripción “(...) de su temor y su gozo, su resistencia y su abandono a las fuerzas que toman posesión de ella y la hacen levitar, la incomparable ingravidez del éxtasis." (Solana, 2011, p. 42)

En su obra The Kitchen. Homage to Saint Therese, 2009, podemos ver, además, una clara alusión al texto de las Fundaciones: "Pues ¡ea!, hijas mías, no haya desconsuelo, cuando la obediencia os trajere empleadas en cosas exteriores; entended que, si es en la cocina, entre los pucheros anda el Señor, ayudándoos en lo interior y exterior." (Teresa de Jesús. Fundaciones $5,8)$

La pieza de Abramović está compuesta por nueve fotografías de gran tamaño y una videoinstalación centradas en la cocina como punto de encuentro para sus confesiones, reflexiones y secretos, donde su cuerpo convive con la relación espiritual y religiosa de su infancia y en contacto directo con su vida más doméstica. Se sirvió de la cocina de la sede en La Laboral de Gijón como telón de fondo y la muestra en el mismo estado que la encontró. En ella representa el paso de los límites de la imagen física y mental utilizando su propio cuerpo.

La artista mezcla lo divino y lo cotidiano, nos presenta el lugar de la casa donde conviven sueños y secretos, en el que se profesan rituales, el lugar en el que mezcla el mundo doméstico y el espiritual. Esa consumación espiritual a la que hace alusión la santa, también es retomada por la artista Julia Fullerton-Batten, exhibiendo obras relacionadas con los fenómenos descritos por Teresa de Jesús en las sextas moradas, momento de éxtasis, de culminación. La levitación es un fenómeno que acompaña en ocasiones al éxtasis, y el arte encuentra un potencial creativo en la imagen plástica de estos fenómenos

Julia Fullerton-Batten en la serie de fotografías titulada In Between presenta unas protagonistas adolescentes que parecen flotar en una atmosfera inquietante donde emergen jugando con la gravedad. En ésta, como en la serie Teenage Stories, se explora la adolescencia femenina como período de transición en el que el cuerpo se vuelve extraño y las emociones inestables, sin anclaje. 


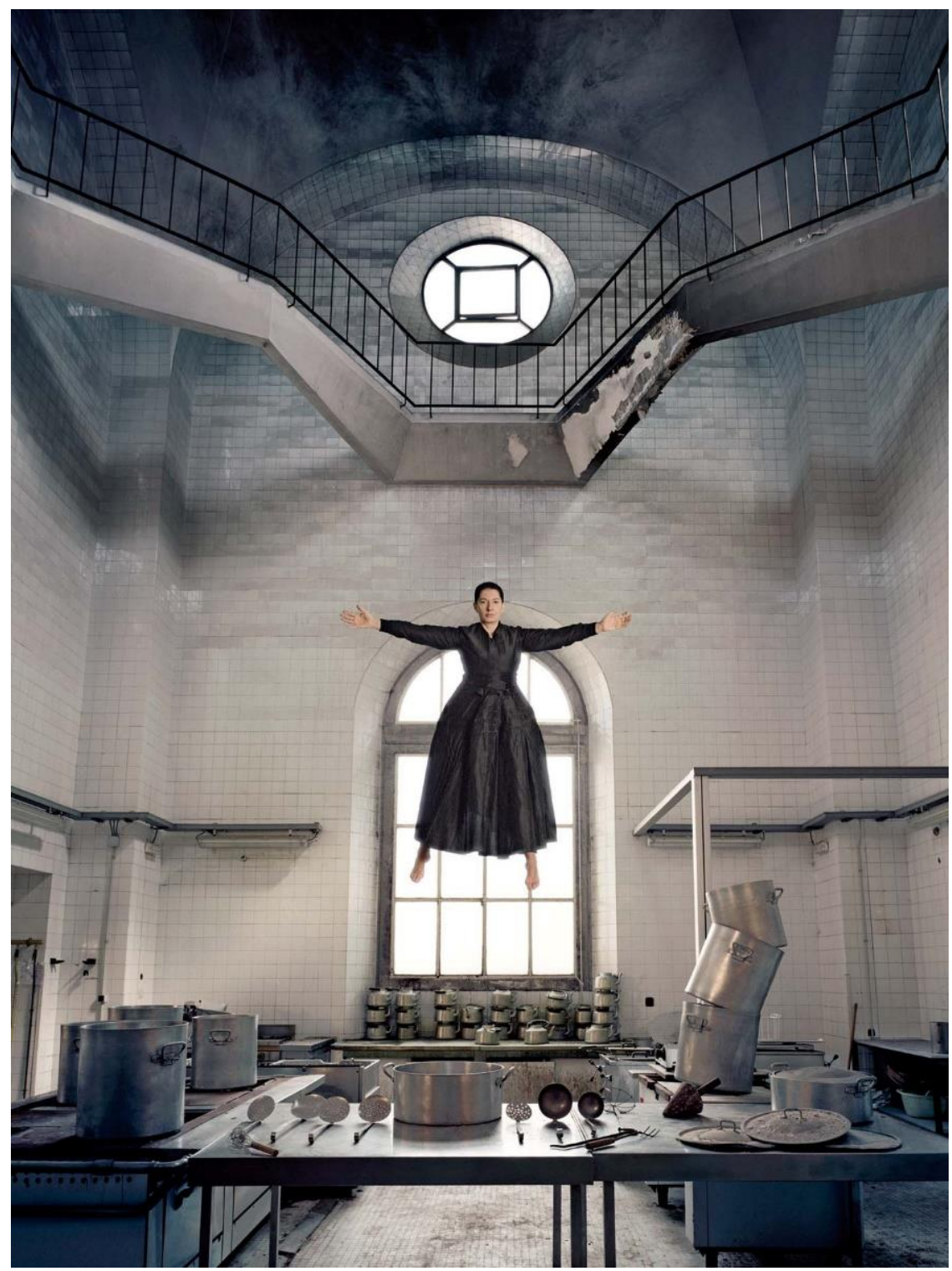

Figura 3. Marina Abramović. The Kitchen I-Homage to Saint Therese, (2009). [CPrint, 220 x $160 \mathrm{~cm}$.]. Recuperada de https://s-media-cache-ak0.pinimg.com/236x /75/ac/9d/75ac9d8764ef299eeb05e9369ce6641e.jpg 
Las fotografías contienen pequeños sucesos dramáticos, aunque sólo sea el viento perturbador que agita una cortina. Mientras tanto, las levitaciones son percibidas a modo de vuelo sereno como una ascensión, y otras veces, de modo peligroso y errático. Una teatralización contemporánea donde quedan inmortalizadas las sensaciones a través de sus rostros enigmáticos y cuerpos suspendidos en el aire. Poses que nos recuerdan al Éxtasis de Bernini. Representaciones que se encuentran entre el placer y la muerte.

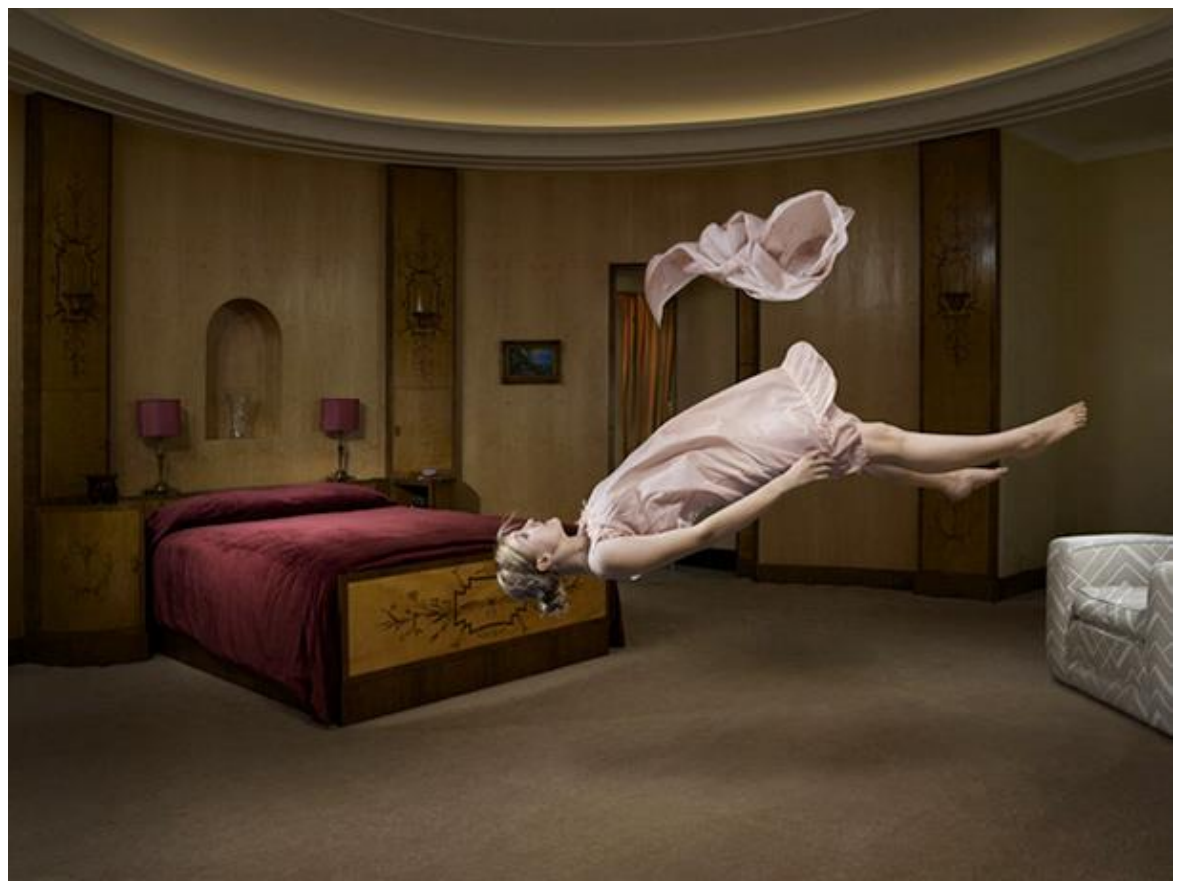

Figura 4. Julia Fullerton-Batten. In Between, (2008). [C-Print, 102 x 137 cm.]. Recuperada de http://foco.me/julia-fullerton-batten/

Los interiores donde residen las protagonistas de las fotografías son enigmáticos, nos hablan del espacio habitado, del espacio secreto, de su morada, y en esa penetración arqueológica se produce un sentir de haber sido visitados, el encuentro con lo sobrenatural, el encuentro con lo divino. En estas obras es mucho más estremecedor el reconocer un espacio íntimo 
penetrado, invadido y violado, que el hecho insólito de la levitación o la ascensión.

La invasión de ese espacio íntimo, la invasión del yo, la intromisión en la soledad del ser, se produce, a veces, con el acecho de voces o con la aparición de visiones que narra la santa. Un hecho que, en la sociedad del siglo XVI, se dictaminaba como brujería. Santa Teresa, al igual que otras místicas como Hildegarda de Bingen u otras heroínas como Juana de Arco, oía voces extrasensoriales y se regocijaba con visiones que la transportaban a otro lugar, un lugar espiritual, deseado profundamente, un camino de conocimiento. A través de voces y visiones se le hacía presente el mensaje de su misión vital, voces a las que la santa alude en las segundas moradas y que van acompañándola en su camino interior.

En este sentido y con motivo de la exposición Nada temas, dice ella, la artista Dora García presenta fuera del espacio expositivo del museo, el proyecto The Hearing Voices Café, 2014-2015, iniciado en Holanda, apostando por una obra de carácter público de intercambio social, ideológico y político.

En su proyecto, la artista utiliza una cafetería como punto de encuentro para reunir a aquellas personas que escuchan voces internas, un hecho que tiene sus raíces en la antipsiquiatría de la década de 1970, como una forma terapéutica de autoayuda. El proyecto Café de las voces de Dora García gira principalmente en torno al intercambio, investigación y desestigmatización. Se compone de diferentes propuestas que incluyen documentos que proporcionan una información detallada sobre el fenómeno, así como un periódico que se actualiza regularmente y material en audio. También hay un archivo de eventos históricos y actividades actuales relacionadas con psiquiatría, resistencia, y el movimiento de los Derechos Civiles, y también con las relaciones entre lenguaje, diversidad mental, capitalismo y arte. Dora García sostiene que "Escucharse a uno mismo es probablemente la definición más elemental de conciencia”. (Martínez, 2016, p. 166)

Este proyecto ofrece un punto de encuentro para una normalidad, lejos ya de ser considerado como enfermedad mental o fruto del demonio. La artista propone una apertura fronteriza rechazando las etiquetas impuestas por una sociedad, explora nuevos territorios e intenta dejar obsoletos aquellos discursos estereotipados. Labor que nos recuerda también a una Santa 
Teresa, que luchó por sus ideales en contra de los cánones marcados por su sociedad.

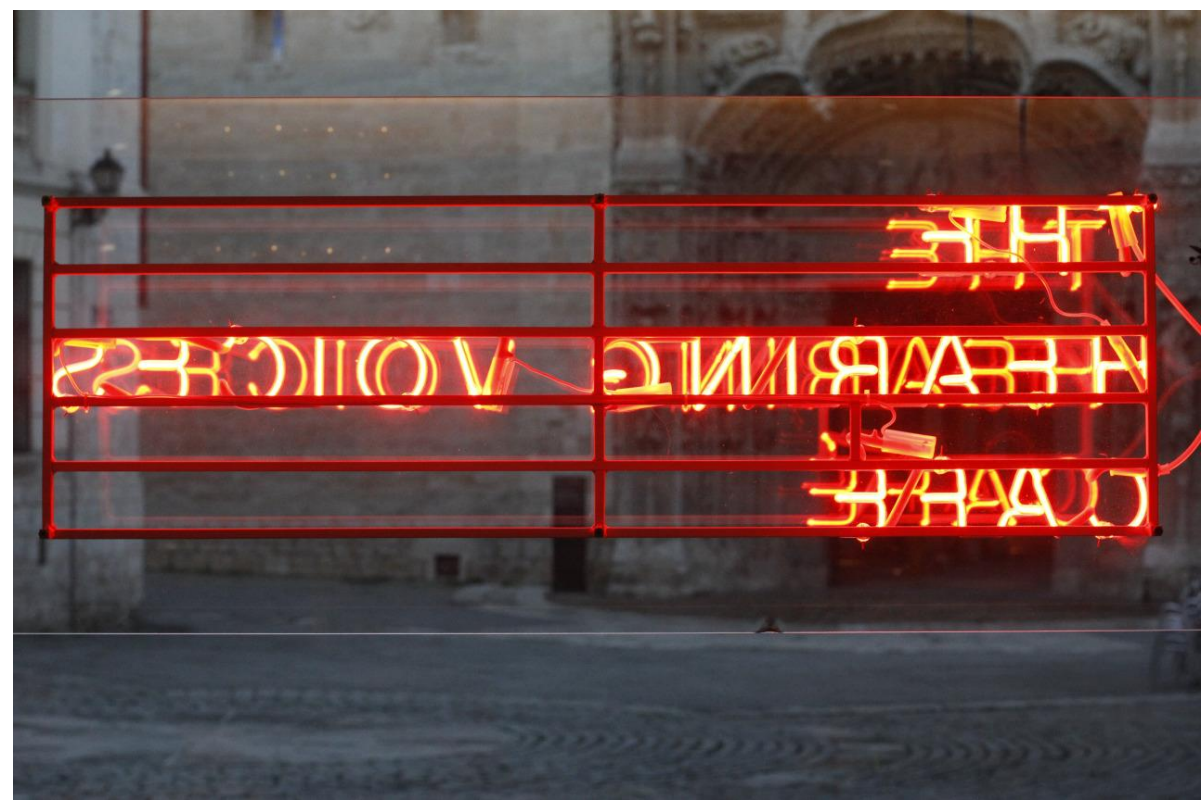

Figura 5. Dora García. El café de los oidores de voces, (2015). Proyecto dentro de la exposición "Nada temas, dice ella" y en colaboración con la Revolución Delirante, Museo Nacional de Escultura de Valladolid. Recuperada de http://elcafedelosoidores devoces.tumblr.com/

Además del éxtasis, la levitación, las visiones o las voces, en esta exploración interior, en ese camino espiritual, Teresa aparece también agitada y perturbada. Movimientos convulsivos calificados posteriormente como histéricos que incluso llevaron a Freud y a su colega Josef Breuer a apodar a Teresa de Jesús como patrona de todas las histéricas (Álvarez, 2004).

En estas enajenaciones y otros arrobamientos que, como estamos viendo, son objeto de representación, cabría señalar las esculturas que realiza Louise Bourgeois (París, Francia, 1911 - Nueva York, USA, 2010) sobre la histeria. En toda su obra, esta artista deja patente la imagen tajante de la opresión 
femenina, aparece representada la expresión inmediata de estados psicológicos, miedos o ansiedades. Hace una clara alusión a esta enfermedad acuñada como enfermedad propia de la mujer en el siglo XIX en dos de sus esculturas. Éstas son: Cell (Arch of Hysteria) y Arch of Hysteria, mostrada en la exposición Nada temas, dice ella.

Cell (Arch of Hysteria) es una instalación que obliga al espectador a adentrarse en un estrecho pasillo para acceder a la obra. En el interior, sobre una cama cubierta con una sábana en la que puede leerse, repetida una y otra vez, la frase Je t'aime, encontramos, arqueado en una postura de extrema tensión, el cuerpo de un hombre desnudo sin cabeza ni brazos. Tal y como señala la artista, esta figura está inspirada en los estudios clínicos sobre la histeria desarrollados a finales del siglo XIX por el neuropatólogo francés Jean-Martin Charcot en el hospital parisino de la Salpêtrière. Sin embargo, cabe destacar que la artista ha realizado una inversión de los roles al emplear un cuerpo masculino, a pesar de que la histeria era considera una patología femenina. De este modo, introduciendo la figura masculina, Bourgeois evidencia esa omisión histórica cuestionando la identificación tradicional entre histeria y el sexo femenino.

Como subraya Michel Foucault en su Historia de la sexualidad, la histerización del cuerpo de las mujeres -que tiene lugar en el siglo XIX- se puede interpretar como una red de estrategias de poder para controlar su sexualidad, y Bourgeois era consciente de esa relación entre histeria y sexualidad cuando señala que, en estas obras, el placer y el dolor se mezclan en un estado de felicidad. En Arch of Hysteria, el deseo sexual es un deseo controlado, donde la figura aparece mutilada.

El cuerpo de la figura, sin cabeza, representa también una exacerbación psíquica genérica y traza un círculo narcisista en el que el dolor y el éxtasis son circuitos de intensidad para cuerpos que, como el de la Santa Teresa de Bernini, no necesitan del acto sexual para colmarse. (Martínez, 2015, p. 136)

Estas obras entroncan con los temas propios de la artista tales como: el sentimiento de culpa, el tabú del sexo, el placer de la fragmentación del cuerpo, pero, a su vez, alude a problemáticas de la práctica médica como la 
influencia que han tenido sus diagnósticos en los prejuicios de género o en cómo la medicina se ha utilizado como instrumento de control moral y cómo ha influenciado en la diferenciación sexual.
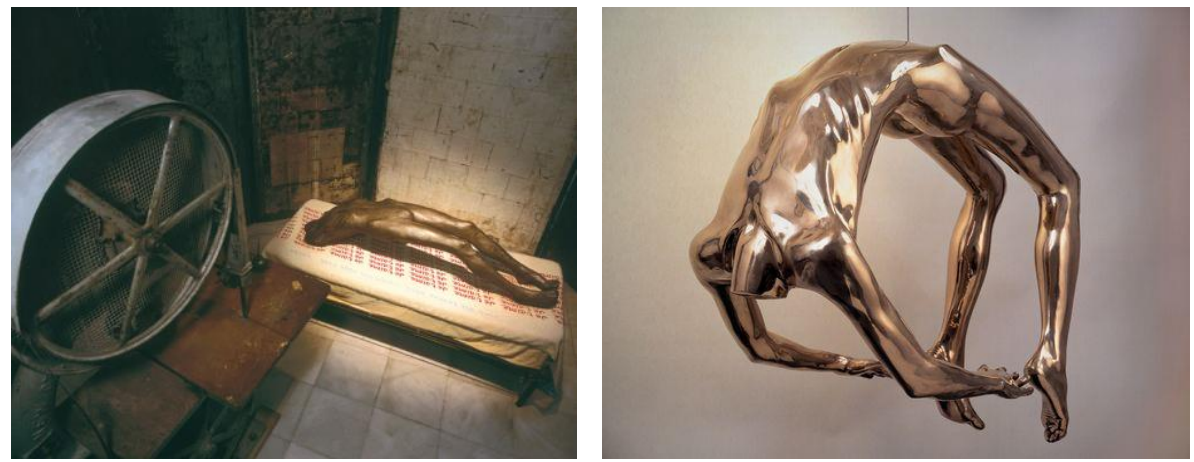

Figura 6. Izquierda. Louise Bourgeois. Cell (Arch of Hysteria) [Celda (El arco de la histeria)], (1993). Acero, bronce, hierro y tela. 302,2 x 368,3 x 304,8 cm. Recuperada de http://www.caac.es/coleccion/artistas/img/bogr.htm

Figura 7. Derecha. Louise Bourgeois. Arch of Hysteria, (1993). Bronce Pulido. 83,8 x 101,6 x 58,4 cm. Recuperada de http://www.psiquifotos.com/2010/05/140-la-musa -augustine-y-ii.html

Por otro lado, Anila Quayyum Agha (Lahore, Pakistan, 1965), de origen pakistaní y residente en la actualidad en Estados Unidos, nos habla en la obra de su propia cultura, la que le sirve como conexión con su propio sentimiento de exclusión como mujer. La artista proviene de un lugar donde la cultura dictaba que las mujeres fueran apartadas de la mezquita, un lugar de creatividad y de comunidad, y en su lugar oraban en casa. Para Anila el destierro y el desarraigo han sido su experiencia durante su desarrollo como mujer. De esta forma, la artista nos habla del exilio, que a través de su obra recobra las reminiscencias de su propia identidad, y que como dice María Zambrano: “(...) sólo, lo inesperable que se advierte con naturalidad, es el primer don del exilio. Aquello que llega como respuesta a una pregunta no formulada" (Zambrano, 1986, p. 32). De esta manera la artista se abandona en medio de la desolación a modo de asceta y mística, en un lugar donde perderse para poder encontrarse. Recordemos que la misma Zambrano 
rememora el último verso de la canción 29 del Cántico espiritual de san Juan de la Cruz: "me hice perdidiza y fui ganada", cambiándole el final: "me hice perdidiza y fui hallada" (Zambrano, 1986, p. 87).

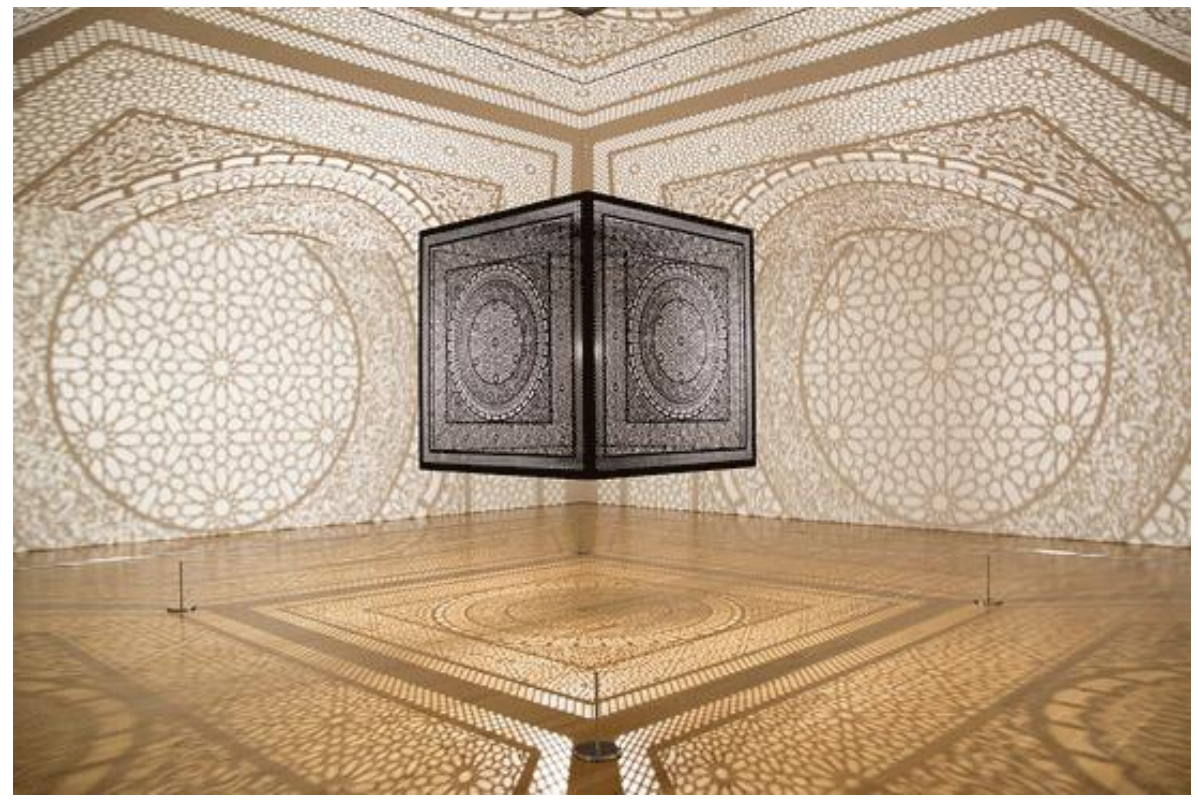

Figura 8. Anila Quayyum Agha. Intersections, (2015). Instalación. Acero cortado con láser. 200,66 x 200,6 x 200,6 cm. Recuperada de http://zgmcm.tumblr.com/post 198244318251/intersections-by-anila-quayyum-agha

Ante ello, Santa Teresa, mujer que bien conoce ese exilio hacia la nada, en busca de ese no lugar para encontrarse a sí misma, nos relata en las terceras moradas de la poca seguridad que podemos tener mientras se vive en este destierro. Desarraigo que le acompaña en su camino místico durante el recorrido por las siguientes moradas hasta alcanzar la comunión espiritual.

En la instalación Intersections, 2013-2015, Anila Quayyum Agha traduce estos sentimientos contradictorios mediante la creación de un espacio contemplativo abierto a todos. Utilizó medios sencillos para lograr el efecto teatral: una sola luz suspendida del techo brilla a través de una caja troquelada pintada de negro. Cada lado de este cubo repite un patrón 
simétrico combinando diferentes elementos decorativos que vio en la Alhambra. Las formas y las líneas geométricas se convierten en sombras que cubren las paredes, el suelo y el techo de la sala e incluso a los visitantes que entran en la estancia. Dentro de la instalación no existe un límite claro o separación; nuestros cuerpos en movimiento cambian la naturaleza del patrón a medida que caminamos libremente a través de su densa silueta.

La artista, mediante este cubo, dispone un habitáculo cerrado y al mismo tiempo abierto que amplifica las paredes del castillo interior en forma de mándalas dibujados. Por su lado, la santa nos recuerda en las primeras moradas dónde conduce la puerta del castillo, nos remite a la profundidad del alma, un alma que es proyectada, luz interior "(...) que es considerar nuestra alma como un castillo todo de un diamante o muy claro cristal, adonde hay muchos aposentos, así como en el cielo hay muchas moradas." (Teresa de Jesús. $1^{a}$ Moradas 1,1)

Anila nos presenta un trabajo de introspección donde propone la expansión lúdica y mística que invita a los espectadores a dialogar con las referencias del pasado y los estímulos del presente:

Su escultura, que está suspendida en medio del espacio, se convierte en metáfora de la fragilidad de las fuerzas que nos sostienen y conecta con la certeza, que también sintió Santa Teresa, de que en cada alma hay una luz interior que impulsa a buscar el propósito existencial de cada uno y a seguir creando para reinventar cada día lo que supone ser artista y mujer. (Martínez, 2016, p. 124)

Si bien son muchas las creadoras actuales cuya temática y reflexión es la espiritualidad, hemos centrado nuestra atención en Ana Mendieta para ejemplificar este camino inefable, cuya obra resulta una clara búsqueda del individuo que le lleva a indagar en respuestas resolutivas ante su propia vida y la sociedad.

Las primeras moradas comienzan con la travesía hacia un viaje interior en busca del alma. Y como metáfora, Teresa nos recuerda que nosotros vivimos fuera del castillo apresados por la materialidad del mundo y, en ese sentido, nos da las claves para empezar ese camino, para comenzar un viaje que nos llevará a esa unión con lo espiritual. 
Si analizamos la obra de Ana Mendieta, podemos comprobar que la artista muestra nuevas maneras de entender el mundo, nuevas maneras de estar en comunión con él y, con ello, expresa tanto sus preocupaciones artísticas como las espirituales. Una búsqueda de su propio castillo interior, donde el primer punto de partida es lanzarse al encuentro de la esencia del ser.

Mi arte se basa en la creencia en una energía universal que todo lo recorre: del insecto al hombre, del hombre al planeta, del planeta a la galaxia. Mis trabajos son las venas irrigadoras de ese fluido. A través de ellas asciende la sabia universal, las creencias originales, los núcleos primordiales y los pensamientos inconscientes que alimentan el mundo. (Picazo, 2001, p. 85)

La obra de la artista explora su espiritualidad a partir de las performances, de acciones inmersas en la naturaleza. Performances que utiliza como ritual de acercamiento para encontrar su esencia, su interior o el lugar donde se halla. “(...) desde aproximaciones diferentes se concreta la voluntad de propiciar experiencias profundas, al crear situaciones límite que nos permiten confrontarnos con el yo, con el paisaje, con el cosmos (...)" (Picazo, 2001, pp. 85-87)

Un camino espiritual, que comienza al dejar aquellos asuntos terrenales para iniciarse en las primeras moradas. Performances de culto religioso, trances para la meditación que incorporan rituales precolombinos o de influencia chamánica que se comprometen con lo trascendental. En la serie Silueta, 1973-1980, encontramos una relación física y vital con la Tierra. Serie en la que representa siluetas femeninas en la naturaleza con materiales que van desde hojas, barro, arena y ramas, hasta sangre, imprimiéndolos en su piel, pintando su perfil en una pared o resaltando la huella de su cuerpo. “(...) el cuerpo femenino, su propio cuerpo, a través del ritual de la muerte y del erotismo, se convierten en lugar y vehículo para establecer nexos de unión con lo sagrado (...)" (Picazo, 2001, p. 129). Estos performances son un ritual de acercamiento al camino para entrar en la morada, en lo más profundo de su ser, donde el proceso además de purgativo se vuelve en ella sanador. Ella misma emerge de entre los elementos naturales. 


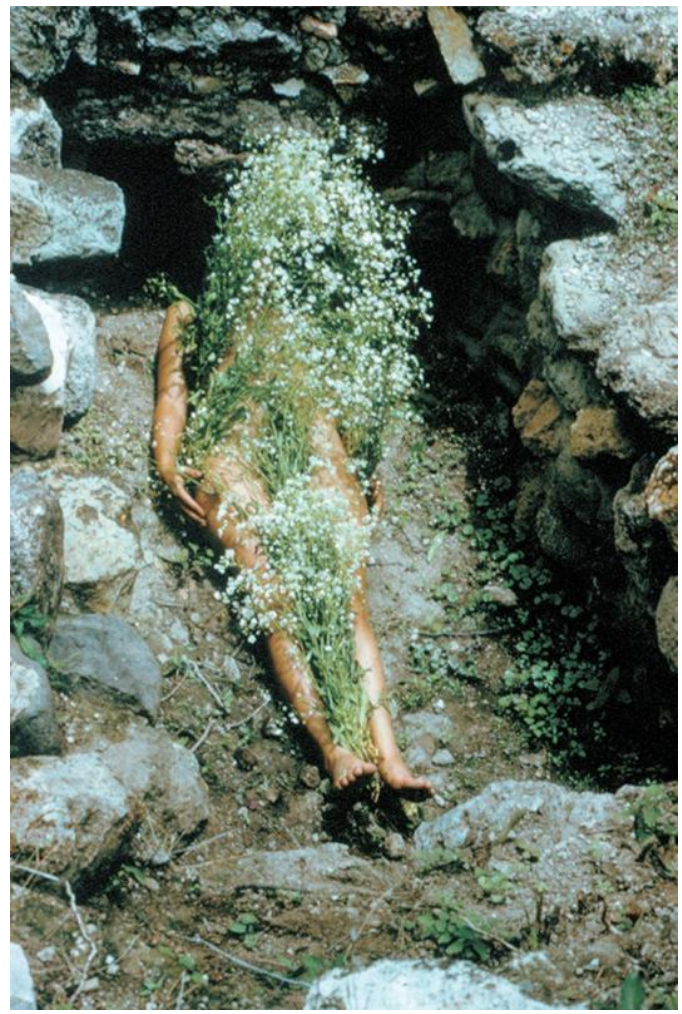

Figura 9. Ana Mendieta. Untitled (Silueta Series, México, 1973-1977). Color photograph from 35 mm slide, 20 x $16 \mathrm{~cm}$. Recuperada de http://

theoddsideofme.tumblr.com/post/148208341748

Para finalizar, quisiéramos proponer la representación de la imagen contemporánea que para nosotros supone Teresa de Jesús. Para ello, nos remitiremos a la obra Leyendo, 2010, de la fotógrafa finlandesa Anni Leppälä (Helsinki, Finlandia, 1981), que nos presenta en un espacio onírico la acción de su protagonista entre la irrealidad y el sueño. Esta fotografía gira entorno a lo íntimo, en especial a la memoria, lo secreto, lo espiritual. A través de un lenguaje sencillo pero cargado de metáforas, nos muestra ese instante donde el tiempo se detiene como una trasposición al éxtasis, una 
imagen cargada de metáforas donde el tiempo y la abstracción son captadas de una manera muy sutil.

En la fotografía, una muchacha de cabello rojo cubre su rostro que lo enmascara como un velo, donde ni el libro, ni su fisonomía desvelan lo que acontece, sólo la posición inquietante e inmóvil, como si de la representación de un ascético de tratase. Imagen donde la mujer es la actriz principal, en este caso una joven lectora. Guillermo Solana en el catálogo Heroínas atribuye a esta imagen simbólica; “(...) ecos de esos poderes espirituales, mágicos o místicos atribuidos a la mujer en la iconografía tradicional." (Solana, 2011, p. 45).

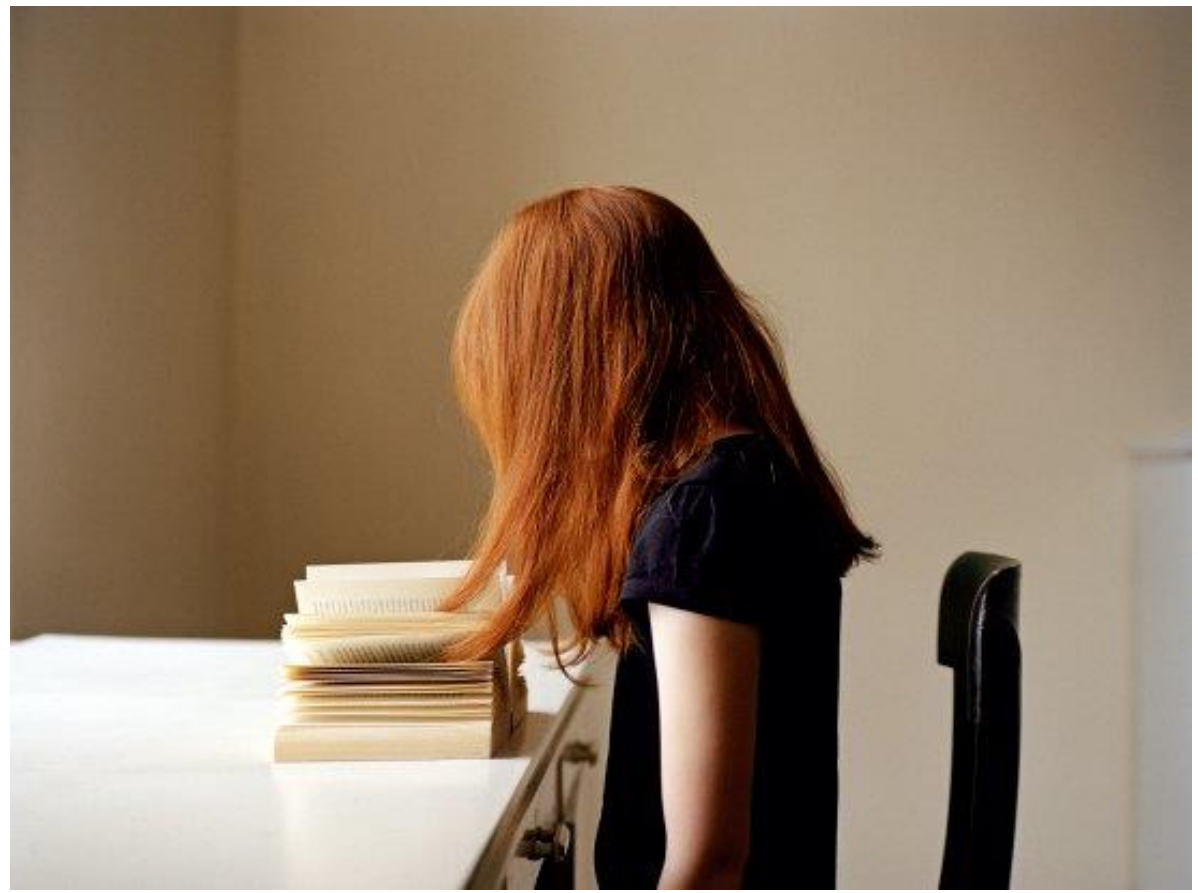

Figura 10. Leppälä, Anni. Leyendo 10. (2010). [C-Print sobre aluminio, $32 \times 2.5 \mathrm{~cm}$.] Recuperada de http://elblogdelablo.files.wordpress.com/2010/03/leyendo-de-anni-lep pc3a41c3a4 
Nos encontramos ante una mujer en su propia habitación frente a un libro, mujer que nos evoca una lectura ensimismada pero se nos manifiesta impenetrable, viviendo a través de otra realidad. Una imagen que construye lo que Virginia Woolf denominó "una habitación propia" o un castillo interior como lo describiría Teresa de Jesús en las Moradas o Castillo interior. Ideologías, posicionamientos y actitudes de una y otra autora que, a nuestro modo de ver y como acabamos de decir, son recogidas en esta fotografía como retrato contemporáneo de la santa. Ante esta posición, la artista nos atrapa y nos hace contemplar la imagen llena de historias que nunca tienen fin y que son un recorrido desde lo perceptible para llegar al interior más profundo del alma, pero sólo a ella pertenece.

En las muchas exposiciones que se han realizado entorno a la figura de Teresa de Jesús y la mística, podemos ver el deseo de mostrar un sustrato antropológico en la búsqueda espiritual, donde las artistas, a través de esa introspección, convierten el arte y la vida en un solo proyecto donde el ser y el estar están en comunión.

En este artículo hemos ido exponiendo la labor de 7 artistas (son muchas más), las que, a través de la espiritualidad, el misticismo y la meditación, y en nuestro caso, a través de la figura de Teresa de Jesús, continúan dando voz a una realidad todavía vigente: la mujer hoy sigue reivindicando su lugar. Todas ellas son quienes mantienen la memoria histórica para combatir el olvido.

Esta búsqueda espiritual es reformulada a modo de proceso creativo a través de diferentes vías o caminos para conseguir esa introversión. Caminos como el religioso, el silencioso, el doloroso, el contemplativo, el meditativo, el visionario, el combativo, para alcanzar ese éxtasis, para alcanzar el encuentro con uno mismo. Aquél que como verdaderamente hizo la santa, alcanza a proteger su castillo interior y a desnudarse ante él, al encuentro de su alma, de lo más puro de la esencia, el yo. Un yo del que el egoísmo no se ha hecho partícipe, un yo puro, un yo entregado a la causa. Heroínas que a través de la lucha constante encontrarán su identidad y se convertirán en voz para una sociedad y espejo de mujeres para reivindicar: soy lo que soy. 


\section{Referencias}

Aliaga, J. V., Oliveira, M., \& Duplaix, S. (2016). Gina Pane: Intersecciones. León: Museo de Arte Contemporáneo de Castilla y León (MUSAC). Álvarez, T. (2004). Teresa a contraluz. La Santa ante la crítica. Burgos: Monte Carmelo.

Ballester, I. (2012). El cuerpo abierto. Representaciones extremes de la mujer en el arte contemporáneo. Gijón: Trea.

Beauvoir, S. de (2003). El segundo sexo. Madrid: Cátedra.

Luceño, G., \& Dorfsfecher, I.-M. (2015). Teresa de Ávila: Mística y transgresora. Valladolid: Diputación de Valladolid.

Martínez, R., Kristeva, J., \& Febo, G. di (2015). Nada temas, dice ella: Cuando el arte revela verdades místicas. Barcelona: Museo Nacional de Escultura - Ediciones Anómadas.

Mingo, A. de, \& Hernández, V. (2015). El cine de la Santa: Teresa de Jesús en la gran pantalla (1925-2015). Toledo: Celya.

Navalón Blesa, N., \& Mañas García, A. (2016). Mujeres heroínas: Santa Teresa de Jesús un referente para el arte contemporáneo. En Nawojowski, J. (Dir.). Temas teresianos para vivir el día a día. Ávila: Universidad de la Mística-CITeS, pp. 211-247.

Picazo, G., Cortés, J. M. G., \& Mascaró, J. (2001). El instante eterno: Arte y espiritualidad en el cambio del milenio. Castellón: Espai d'Art Contemporani de Castelló (EACC). Generalitat Valenciana.

Rico, P. J., Abramović, M., \& Wulffen, T. (1998). Marina Abramović: The Bridge/El Puente. Valencia: Consorcio de Museos de la Comunidad Valenciana. Generalitat Valenciana.

Ros, C. (2011). Teresa de Jesús, esa mujer. Madrid: San Pablo.

Solana, G., Villa, R. de la, Gallardo, C., \& Valcárcel, A. (2011). Heroínas. Madrid: Museo Thyssen-Bornemisza - Fundación Caja Madrid.

Teresa de Jesús (2000). Obras completas (5a ed.). Madrid: Editorial de Espiritualidad (EDE).

Underhill, E. (2006). La mística: Estudio de la naturaleza y desarrollo de la conciencia espiritual (Trad. C. Martín). Madrid: Trotta. 
Vettesse, A. (2013). El arte contemporáneo: Entre el negocio y el lenguaje. Madrid: Rialp.

Zambrano, M. (1986). Claros en el bosque. Barcelona: Seix Barral.

Natividad Navalón: Artista y Catedrática de Escultura en la Universitat Politècnica de València. Directora del grupo de investigación Nuevos Procedimientos Escultóricos.

\section{Email address: natividad.navalon@gmail.com}

Alejandro Mañas: Artista y doctorando del grupo de investigación Nuevos Procedimientos Escultóricos.

\section{E-mail address: alejandro.manas@hotmail.com}

Teresa Cháfer Bixquert: Artista y Titular de Universidad en la Universitat Politècnica de València. Profesor investigador del grupo de investigación Nuevos Procedimientos Escultóricos.

\section{E-mail address: teresachafer@gmail.com}

Contact Address: Facultat de Belles Arts. Departament d'Escultura. Universitat Politècnica de València. Camino de Vera s/n. 46022- Valencia (España). 